\title{
Can we make sense of MacFarlane's relative truth?
}

\section{Matías Gariazzo}

Facultad de Humanidades y Ciencias de la Educación, Universidad de la República

Instituto de Filosofía

Montevideo

Uruguay

Facultad de Humanidades y Educación, Universidad de Montevideo

Departamento de Filosofía

Montevideo, Montevideo

Uruguay

mgariazzo1@gmail.com

Article info

CDD: 501

Received: 18.11.2016; Accepted: 24.11.2016

DOI: http://dx.doi.org/10.1590/0100-6045.2017.V40N2.MG

Keywords

Truth relativism

Assessment sensitivity

Monadic truth

Non-monadic truth

\begin{abstract}
John MacFarlane's truth relativism $(2005,2007,2011,2014)$ makes use of two notions of propositional truth: a monadic assessment sensitive one taken to be our ordinary truth notion, and a non-monadic one that is meant to account for the assessment sensitivity of the former notion. Some authors (Cappelen and Hawthorne, 2009, 2011; Montminy, 2009; Soames, 2011) contend that any theory introducing a technical non-monadic truth notion has to make sense of it (i.e. show that it is a truth notion) by defining or characterizing it in terms of ordinary monadic truth. First, I give some reasons why the relativist should not discard this approach to make sense of the notion of truth relative to a context of assessment. Second, I argue that an illuminating characterization of this notion must provide an answer to a dilemma Paul Boghossian (2011) poses to the relativist. Third, I single out the characterization that can answer this dilemma. Finally, I contend that the relativist still needs to show that this solution works for each case subject to a relativist treatment.
\end{abstract}

Manuscrito - Rev. Int. Fil. Campinas, v. 40, n. 2, pp. 39-70, abr.-jun. 2017. 
In order to account for our use of several expressions (e.g., predicates of personal taste, knowledge ascriptions or epistemic modals), John MacFarlane $(2005,2007,2011,2014)$ makes use of two notions of propositional truth: a monadic assessment sensitive one allegedly expressed in English by 'true,' and a triadic one expressed by a metalinguistic predicate from the relativist theory. ${ }^{1}$ The first notion is monadic insofar as its extension is a set of propositions and not a set of ordered n-tuples, whereas it is assessment sensitive because it has an extension relative to parametric values in the circumstances of evaluation (e.g. a standard of taste, a standard of knowledge or an information state) that are determined by the context of assessment instead of by the context of use. The triadic truth notion, in turn, relates propositions to contexts of use and contexts of assessment and is meant to account for the assessment sensitivity (and use sensitivity) of the monadic notion. ${ }^{2}$ On this framework, the accuracy (i.e. correctness in a truth-derived sense) of assertions, acceptances and rejections of assessment sensitive propositions is itself assessment sensitive. Insofar as we need a context of assessment in addition to a context of use (i.e. a context where a proposition is asserted, accepted or rejected) to assess for truth an

${ }^{1}$ This notion belongs to the second stage of MacFarlane's framework (2014, pp. 55- 64, pp. 76-81). In his framework, we first recursively define sentential truth relative to contexts and indices and propositional truth relative to circumstances of evaluation, and then, in a second stage, we define sentential and propositional truth relative to a context of use and a context of assessment. The second definition of propositional truth, which he considers as post-semantic, allows us to determine which circumstance (or set thereof) is relevant to assess a proposition for simple truth and has direct implications on how assertions, acceptances and rejections of propositions are to be assessed.

${ }^{2}$ It is worth noting that for MacFarlane (2005, p. 309; 2014, pp. 60-61) there is no ontological difference between contexts of use and contexts of assessment. The difference suggested by the labels 'use' and 'assessment' has to do with the different roles we give to these contexts in the second stage of the relativist framework: one can think of a context either as a possible situation of use or as a possible situation of assessment of a use of a sentence and a proposition. To be sure, when making an assertion, one's context of use is one's context of assessment.

Manuscrito - Rev. Int. Fil. Campinas, v. 40, n. 2, pp. 39-70, abr.-jun. 2017. 
assessment sensitive proposition, we also need it to assess for accuracy an assertion, acceptance or rejection of such a proposition.

MacFarlane (2007, 2014) adduces a range of disagreements and retractions as the main evidence for his proposal. ${ }^{3}$ Consider an alleged case of disagreement where John sincerely and assertively utters sentence (1) and Ann does the same with sentence (2):

Mutton is tasty.

Mutton is not tasty.

According to the relativist, we would have at the same time the impression that John and Ann disagree with each other and the impression that both of them are perfectly entitled to make their assertions and have the beliefs their assertions express-what else but their own taste could license their assertions and beliefs? Max Kölbel (2003, pp. 53-54; 2009, pp. 389-391) introduced the category of faultless disagreement to describe such cases: according to him, these cases involve a genuine disagreement between two people that are free of any fault. MacFarlane's treatment of "tasty" would vindicate these appearances by taking this predicate as invariantly expressing a monadic assessment sensitive property, i.e. a monadic property whose extension (the set of tasty things) can vary with the context of assessment. As a result of this, John's and Ann's assertive utterances of (1) and (2) would express propositions that contradict each other (i.e. that cannot be jointly true at a circumstance) and are true or untrue depending on the context of assessment, and so the accuracy of these assertions would also depend on this context. Thus, John and Ann would be fault free in the sense that their assertions would be accurate relative to their own respective contexts of assessment, and they would genuinely disagree with each other insofar as their assertions could not be jointly accurate at a single context of assessment.

${ }^{3} \mathrm{~A}$ retraction is a speech act by means of which someone takes back another speech act she made (typically an assertion) (MacFarlane 2014, pp. 108-110). Sincere retractions of assertions can be seen as manifestations of disagreements of a special kind: those where the agent disagrees with her previous self.

Manuscrito - Rev. Int. Fil. Campinas, v. 40, n. 2, pp. 39-70, abr.jun. 2017. 
Some authors (Cappelen and Hawthorne, 2009, 2011; Montminy, 2009; Soames, 2011) contend that any theory that introduces a technical non-monadic truth notion has to make sense of it (i.e. show that it is a truth notion) by defining or characterizing it in terms of ordinary monadic truth. In particular, MacFarlane would have to make sense of the notion of truth relative to a context of assessment in such a way, which in turn would allow him to make sense of the assessment sensitivity of ordinary truth. ${ }^{5}$ MacFarlane $(2005,2014)$ endorses a different approach to make sense of his non-monadic truth notion. In this essay I provide some reasons for not discarding the characterization or definitional approach, and single out the characterization that could make sense of truth relative to a context of assessment. Whether this characterization can actually do this should be determined on a case-by-case basis, namely in connection with particular expressions (e.g. predicates of personal taste) for which relativist treatments have been proposed. Since we do not carry out this task here, we ultimately leave open the question of whether the relativist can make sense of her non-monadic truth notion. Be that as it may, as we shall suggest, there are better prospects of accomplishing this task in the case of evaluative predicates like personal taste, moral or aesthetics predicates than in other cases.

In the first section I present the two approaches to making sense of the notion of truth relative to a context of assessment mentioned in the

\footnotetext{
${ }^{4}$ As we explained, MacFarlane's technical truth notion is a triadic one relating propositions to contexts of use and contexts of assessment. Be that as it may, we shall assume that propositions are use sensitive at most with respect to the world (i.e. the context of use determines at most the world that is relevant to assess a proposition for truth), and this assumption will allow us not to mention the context of use when talking about MacFarlane's non-monadic notion of propositional truth.

${ }^{5}$ It is worth pointing out that Herman Cappelen and John Hawthorne (2009) assume that truth relativism cannot define or characterize its non-monadic truth notion in terms of monadic truth, and so claim that relativists must reject the explanatory priority of the latter notion. MacFarlane (2011) argues that this is not so. However, he adopts a different approach to make sense of his triadic truth notion.
}

Manuscrito - Rev. Int. Fil. Campinas, v. 40, n. 2, pp. 39-70, abr.-jun. 2017. 
previous paragraph, and provide some reasons for not dismissing the characterization approach. In the second section I show that an illuminating characterization of this non-monadic truth notion in terms of monadic truth, must provide an answer to a dilemma that Paul Boghossian (2011, pp. 60-66) introduces for truth relativism. In the third section I argue that the default understanding of the metalanguage of the relativist theory prevents us from providing an explanation of this nonmonadic truth notion in terms of monadic truth that solves Boghossian's dilemma. In the fourth section I present an alternative interpretation of the relativist metalanguage that could provide the required explanation. In the fifth section I contend that the relativist still needs to show that this solution works for each case subject to a relativist treatment. Finally, the sixth section gives a short summary of the paper.

\section{Two approaches to making sense of relative truth}

As MacFarlane (2005, p. 312; 2014, p. 97) points out, it is not clear that the notion of truth admits of a relativization to assessors. Following Jack Meiland (1977), MacFarlane states the question as a dilemma:

If 'true' as it occurs in 'true for $\mathrm{X}$ ' is just the ordinary, nonrelative truth predicate, then it is unclear what 'for $\mathrm{X}$ ' adds. ${ }^{6}$ On the other hand, if the occurrence of 'true' in 'true for $\mathrm{X}$ ' is like the 'cat' in 'cattle' -an orthographic, not a semantic, part- then the relativist needs to explain what 'true-for- $\mathrm{X}$ ' means and what it has to do with truth, as ordinarily conceived. (MacFarlane 2005, p. 312; 2014, p. 97)

According to this, the relativist has to make sense of the notion of truth relative to a context of assessment. And this amounts to making sense of the assessment sensitivity of the ordinary monadic truth notion, which the just-mentioned non-monadic truth notion is meant to account for.

${ }^{6}$ As MacFarlane (2014, p. 97) points out, 'for X' could be used to state what the opinion of $\mathrm{X}$ about something is, but this is not the understanding of this expression that the relativist is after.

Manuscrito - Rev. Int. Fil. Campinas, v. 40, n. 2, pp. 39-70, abr.jun. 2017. 
As we shall see in this section, there are at least two different approaches to deal with this problem.

As we explained, one approach consists in defining or characterizing the notion of truth relative to a context of assessment in terms of the ordinary truth notion. According to this approach, the relativist should explain the sense of her non-monadic truth predicate in terms of the ordinary truth predicate -which, we can assume, expresses a notion we already grasp to some extent. This, in turn, would allow us to conceive of ordinary truth as assessment sensitive. Martin Montminy (2009, pp. 349-352) elaborates this point.

Montminy argues that there should be a way of paraphrasing what we say by using MacFarlane's non-monadic truth predicate by means of using our ordinary one. Otherwise, the relativist can be accused of changing the subject; she can be accused, for instance, of ultimately talking about what seems true to an assessor (under appropriate conditions, if you like), contrary to her initial purpose. The requirement of providing such an explanation may not be, as Montminy (2009, p. 350) stresses, a requirement to provide a reductive definition using the ordinary notion of what we say by using the non-monadic one. To conceptually link the two notions and preserve the subject matter it is arguably sufficient to provide a characterization of the non-monadic notion in terms of the ordinary one that is extensionally adequate. And we can find examples of such ways of linking a non-monadic truth notion with the monadic ordinary one that seem pretty natural. For instance, we can link the dyadic truth notion relating propositions to possible worlds to our ordinary truth notion by taking truth in the actual world as extensionally equivalent to truth, ${ }^{7}$ and taking our talk of truth in non-actual worlds as

\footnotetext{
${ }^{7}$ It is worth pointing out that, as Scott Soames (2011, p. 127) shows, we should use a non-rigid description such as 'the actual world' in stating this equivalence, and not a directly referential expression like the name '@,' which refers to the actual world. The reason is that a proposition that is true at @ has the property of being true at@ in every possible world, and so being true at@ is an essential property of any proposition that has it, unlike the property admittedly expressed by 'true.' Therefore, even though these properties are coextensive at @, they are different properties that can have different extensions. Analogous remarks can
}

Manuscrito - Rev. Int. Fil. Campinas, v. 40, n. 2, pp. 39-70, abr.-jun. 2017. 
having at least an extensional correlate in our ordinary counterfactual talk about truth: to say that something (a proposition) is true/untrue/false in (non-actual) world $w$ is equivalent to saying that it would be true/untrue/false if such and such were the case. ${ }^{8}$ Similarly, if one accepts time-neutral propositions, one may hold that saying that proposition $p$ is true/untrue/false at time $t$ is equivalent to saying that $p$ is true/ untrue/false (if $t$ is the present time), saying that $p$ was true/ untrue/false when toccurred (if $t$ is in the past) or saying that $p$ will be true/ untrue/false when toccurs (if $t$ is in the future).

According to this line of reasoning, if there were no such connection between the ordinary truth predicate and the relativist non-monadic one, there may be no compelling reason to consider the latter as expressing a truth notion and so no compelling reason to consider our ordinary truth notion as assessment sensitive. In other words, the absence of such a connection would suggest that MacFarlane's truth relativism fails to account, by means of its non-monadic truth predicate, for the alleged assessment sensitivity of the ordinary monadic truth notion. Accordingly, the relativist could be seen as talking about some other notion whose significance -e.g. its alleged role in the relativist's account of assertion, disagreement and retraction- would be dubious.

The second approach to making sense of the relativist non-monadic truth notion is the one MacFarlane (2005, pp. 312-322; 2014, pp. 97-101) endorses. MacFarlane proposes to make sense of this notion by describing the role it plays in a broader theory of language use; more precisely, by describing its connection to the speech act of assertion. The idea is that, even though a definition of the relativist's triadic truth predicate that merely establishes its extension over a class of propositions and contexts does not give us the grasp of the notion it expresses that we are looking for, we could have such a grasp if we

be made concerning temporal semantics and the equivalence between truth and truth at the present time.

${ }^{8}$ In the same vein, Soames (2011, p. 124) proposes to understand possible worlds as properties and to take the truth of a proposition $p$ at (non-actual world) $w$ as the fact that $p$ would be true were the universe to instantiate $w$.

Manuscrito - Rev. Int. Fil. Campinas, v. 40, n. 2, pp. 39-70, abr.jun. 2017. 
combined this definition with an account of the different illocutionary forces -e.g. assertoric force- with which one can put forth a sentence. In order to illustrate this point, MacFarlane asks us to consider the following analogy taken from Dummett (1959). Consider the concept of winning in chess. One could have a definition of 'winning in chess' that states under which configurations of pieces on the chess board White or Black counts as winning. But if one only had this knowledge one would miss a crucial aspect of the concept of winning in chess. According to Dummett, the missed aspect could be that winning in chess is what we aim at in playing this game. In the same way, a definition that merely fixes the extension of a truth predicate would not allow someone who does not know the significance of applying it to sentences and propositions to understand the concept it expresses. On Dummett's opinion, what needs to be added to Tarski's (1956) classical truth definition in order to understand the defined notion, could be the information that truth is the aim of assertion (i.e. the information that, when making sincere assertions, we aim to assert true propositions). Similarly, MacFarlane thinks that in order to understand his triadic truth notion we need to somehow connect it to our practice of making assertions.

MacFarlane $(2005,2007,2014)$ proposes two ways of doing this. In the first place, he (2014, pp. 102-111) provides what he considers three constitutive truth norms of assertion that allow us to account for the act of asserting an assessment sensitive proposition:

(M) An agent is permitted to assert proposition $p$ at context $c$ only if $p$ is true as used at $c$ and assessed from $c$.

(RT) An agent in context $c_{2}$ is required to retract an (unretracted) assertion of $p$ made at $c_{1}$ if $p$ is not true as used at $c_{1}$ and assessed from $c_{2}$.

(RJ) An agent in context $c_{2}$ is permitted to reject an assertion of $p$ made at $c_{1}$ if $p$ is not true as used at $c_{1}$ and assessed from $c_{2}$.

In the second place, MacFarlane (2005, pp. 318-321; 2007, pp. 27-29) extends Brandom's account of assertion as a commitment to truth to make room for contexts of assessment. On MacFarlane's opinion, we

Manuscrito - Rev. Int. Fil. Campinas, v. 40, n. 2, pp. 39-70, abr.-jun. 2017. 
can account for the act of asserting an assessment sensitive proposition $p$ by means of commitment $W_{R}$, and possibly also by means of commitments $V_{R}$ and $R_{R}$ :

$W_{R}$ : Commitment to withdrawing the assertion (in any future context $\mathrm{c} 2$ ) if $\mathrm{p}$ is shown to be untrue as used at $\mathrm{c} 1$ and assessed from c2.

$V_{\mathrm{R}}$ : Commitment to vindicating the assertion when it is appropriately challenged, by providing grounds for the truth of $\mathrm{p}$ as used at $\mathrm{c} 1$ and assessed from $\mathrm{c} 2$ (the context at which the challenge is being met), or perhaps by deferring to someone else who can.

$\mathrm{R}_{R}$ : Commitment to accepting responsibility (at any future context c2) if on the basis of this assertion someone else takes $p$ to be true as used at $\mathrm{c} 1$ and assessed from $\mathrm{c} 2$, and it proves not to be.

Regarding the example introduced at the beginning of this paper, John's assertion that mutton is tasty would be governed by (M), (RT) and (RJ), and would carry at least commitment $W_{R}$. Accordingly, John would be -because of (M) and (RJ)- entitled to make his assertion and reject Ann's assertion that mutton is not tasty, and -because of (RT) and $W_{R^{-}}$ John could have to admit that he was wrong if his context changed so that a taste standard according to which mutton is not tasty became relevant (typically, if his personal taste changed). And, of course, analogous remarks could be made concerning Ann's assertion. On MacFarlane's view, this accords with and vindicates our use of "tasty", given that we see ourselves as disagreeing with people who apply this predicate differently from us, and we are disposed to retract our assertions that something is tasty when we cease to find it tasty because of a change in our taste. Thus, by accounting for a pattern of linguistic usage that we could recognize as our own, these rules and commitments would make sense of MacFarlane's non-monadic truth notion.

Advocates of the characterization approach (Cappelen and Hawthorne, 2009; Montminy, 2009; Soames, 2011) might contend that principles $(\mathrm{M})$ and $(\mathrm{RT})$ or $W_{\mathrm{R}}, V_{\mathrm{R}}$ and $R_{R}$ cannot on their own show that the notion of truth relative to a context of assessment is a truth notion.

Manuscrito - Rev. Int. Fil. Campinas, v. 40, n. 2, pp. 39-70, abr.jun. 2017. 
After all, the reasoning goes, in conferring empirical significance on the theory via the above stated principles, we could still be seen as testing a theory about a notion such as seems true to an assessor (under appropriate conditions, if you like), contrary to what is intended. MacFarlane, in turn, considers that his approach is sufficient to make sense of the notion of truth relative to a context of assessment. I close this section by offering two reasons not to dismiss the characterization approach.

To begin with, there is a significant difference between the truth predicates or notions that Dummett and MacFarlane respectively intend to make sense of. In Dummett's example, it is assumed that the only knowledge the Tarskian semantic definition gives us is how the extension of the defined predicate is recursively established, and the added information takes us to a post-semantic or pragmatic level. In doing so, the semantically defined notion is arguably identified with ordinary truth. ${ }^{9}$ In turn, MacFarlane's definition of truth at a pair of contexts already lies at a post-semantic level, and as such it is meant to inform us not just about how the extension of this notion is established, but also about how assertions are to be assessed for accuracy. ${ }^{10}$ Once we have this information, it is obvious how to extend a traditional nonrelativist account of assertion in terms of truth norms or truth commitments in order to make room for contexts of assessment: we just need to assume that the truth notion present in this account is assessment sensitive, and make its dependence on a context of

9 To be sure, Tarski (1956) defines a predicate 'true in L' that can only be applied to the sentences of a particular language L. Still, if one is willing to talk of propositions, one can see the definition as telling us under which conditions the content of each sentence of $\mathrm{L}$ is simply true.

${ }^{10}$ In MacFarlane's framework, we first recursively define sentential truth relative to contexts and indices and propositional truth relative to circumstances of evaluation, and then, in a second post-semantic stage, we define propositional truth relative to a context of use and a context of assessment. As we observed, the second definition, unlike the first ones, is meant to have direct practical relevance. As long as the context of assessment in addition to the context of assertion (i.e. the context of use) is needed to assess the asserted proposition for truth, it is also needed to assess the assertion for accuracy.

Manuscrito - Rev. Int. Fil. Campinas, v. 40, n. 2, pp. 39-70, abr.-jun. 2017. 
assessment explicit. Thus, if we have doubts about the meaningfulness of MacFarlane's post-semantic triadic truth predicate, these doubts can hardly be assuaged by principles like (M) and (RT), or $W_{R}, V_{R}$ and $R_{R}$. An obvious strategy to assuage these doubts is to give some explanation of the non-monadic truth notion in terms of the ordinary one.

Besides, there is a presumption that, in case the relativist nonmonadic truth predicate is meaningful, there is a way to explain its sense in terms of the ordinary one. This presumption comes from the fact that in the paradigmatic cases where a non-monadic truth notion is introduced to account for an aspect of the ordinary one -e.g. in the case of possible world semantics and temporal semantics- an explanation of the former notion in terms of the latter can be given. Accordingly, in case the relativist claimed that there was no such explanation of her nonmonadic truth notion, doubt could be cast on its intelligibility.

According to what we said, even if by helping us to test the relativist theory, MacFarlane's approach helps us to make sense of its nonmonadic truth notion, there is reason not to dismiss Montminy's approach. In the next section I present a dilemma that Paul Boghossian (2011, pp. 60-66) levels against truth relativism. As we shall see, an explanation of the relativist non-monadic truth notion in terms of ordinary truth has to provide an answer to this dilemma.

\section{A dilemma for truth relativism}

Boghossian (2011, pp. 61-62) motivates his dilemma by means of an argument he calls the 'Argument from (Perspectival) Immersion.' This argument is a development of an objection that Richard (2008, p. 132) makes to the notion of faultless disagreement as a phenomenon lending support to truth relativism. As we explained in the introduction, a faultless disagreement (Kölbel 2003, 2009) is a case involving a genuine disagreement between two people that are free of any fault. According to the relativist, the example of a case lending support to truth relativism that we presented at the beginning belongs to this category. As we shall see, Boghossian (2011, p. 65) considers that the conclusion of the Argument from Immersion (i.e. the inexistence of faultless 
disagreements) is not in itself problematic for truth relativism. What is meant to be problematic for this view is the dilemma he extracts from the argument.

Richard's objection shows that we cannot make sense of the notion of faultless disagreement if the relevant notion of fault -and so the relevant notion of accuracy- is a monadic assessment sensitive one. From any context of assessment, two people sincerely asserting assessment sensitive propositions that are inconsistent with each other (i.e. that cannot be jointly true at a circumstance of evaluation) and use sensitive at most with respect to the world, cannot be both fault free; ${ }^{11}$ from any context of assessment, if one assertion is accurate the other is not accurate, and so at least one of the disagreeing parties should be judged to be at fault because of asserting an untrue proposition. Regarding the example presented at the beginning, relativism yields the result that there is no context of assessment relative to which John's assertion and Ann's assertion are both accurate, since there is no such context relative to which the proposition that mutton is tasty and the proposition that mutton is not tasty are jointly true. Thus, for any rational committed assessor, that is a rational assessor occupying a context of assessment that determines a truth-value or lack thereof for the asserted propositions (as used at the context of the asserter), there cannot be faultless disagreements. And from this we could conclude that there cannot be faultless disagreements, since such an assessor could not claim that there are.

Boghossian offers the following version of this argument and then derives a dilemma from it that the relativist would face (we assume, with Boghossian, that propositions are use sensitive at most with respect to

11 As MacFarlane (2007, p. 22: 2014, pp. 126-127) shows, if two people occupying the same world sincerely asserted propositions that are neutral with respect to a non-world parameter that is initialized by the context of use, the mutual inconsistency of these propositions would not be a sufficient condition for disagreement understood as involving the preclusion of the joint accuracy of the two assertions (as assessed from a single context).

Manuscrito - Rev. Int. Fil. Campinas, v. 40, n. 2, pp. 39-70, abr.-jun. 2017. 
the world and that both A and B occupy the actual world, and so allow ourselves not to make reference to contexts of use): ${ }^{12}$

1) A judges that $p$ and $B$ judges that not- $p$.

2) Proposition $p$ is true relative to A's context of assessment and proposition not- $p$ is true relative to B's context of assessment.

3) If $p$ is true relative to A's context of assessment, then the proposition that it is true that $p$ is true relative to A's context of assessment (i.e. instances of the schema 'it is true that $p$ iff $p$ ' are true within a context of assessment).

4) If $A$ judges that it is true that $p$ then $A$ must, on pain of incoherence, judge that it is untrue that not-p.

5) If $A$ judges that it is untrue that not- $p$ then $A$ must, on pain of incoherence, consider that anyone who judges that not-p (e.g. B) is making a mistake (being inaccurate). ${ }^{13}$

6) Therefore, A can correctly judge that B is making a mistake and so cannot regard the disagreement with $\mathrm{B}$ as faultless.

7) Therefore, the disagreement between A and B is not faultless.

12 I have introduced some changes to Boghossian's presentation of this argument to fit my expository purposes. In particular, I talk of contexts of assessment where he talks of perspectives, and I chose to talk of a proposition being untrue instead of being false, since it is not necessary for the effectiveness of the argument and the dilemma derived from it to assume that propositions are either true or false.

${ }^{13}$ Non-indexical contextualist views rejct 5 and so are not subject to the dilemma we are about to present. Such views relativize propositional truth to a non-standard parameter (e.g. a standard of taste parameter) but do not treat accuracy as relative, since they take the value of this parameter to be fixed by the context of use. Accordingly, for a proponent of such a view, someone can be right to assert or accept something untrue, and someone can be wrong to assert or accept something true. An asserted proposition (e.g. the proposition that mutton is tasty) can deserve a different truth-value assessment at one's context from the one it deserves at the context of the assertion, and the only context that matters to assess the assertion for accuracy is the latter context (i.e. the context of use).

Manuscrito - Rev. Int. Fil. Campinas, v. 40, n. 2, pp. 39-70, abr.jun. 2017. 
Let us consider this argument as applied to the example introduced at the beginning. First, substituting A for John, B for Ann and $p$ for the proposition that mutton is tasty, the argument would show that, on the relativist's view, John cannot rationally see his disagreement with Ann as faultless; from his context of assessment, the proposition that mutton is not tasty is untrue and so Ann's assertion -unlike his- is inaccurate. On the other hand, substituting A for Ann, B for John, and $p$ for the proposition that mutton is not tasty, the argument would also show that Ann cannot rationally see this disagreement as faultless; from Ann's context of assessment, the proposition that mutton is tasty is untrue and so John's assertion -unlike hers- is inaccurate. More generally, the argument purports to show that for any rational committed assessor (e.g. for anyone whose context allows her to assess the proposition involved in a disagreement) there cannot be faultless disagreements. And from this, we could conclude that there cannot be such disagreements.

Having presented the Argument from Immersion, it is worth stressing that, for Boghossian (2011, p. 65), the conclusion 7 in itself is not what is problematic for the relativist. After all, a relativist like MacFarlane is happy to concede that there cannot be faultless disagreements once the notion of fault at stake (i.e. the notion of inaccuracy) is taken to be -as the intended notion of fault from the Argument from Immersion is- the one responsible for our intuitions of disagreement, ${ }^{14}$ since for MacFarlane this is a monadic assessment sensitive notion. And, as he (2014, pp. 133-136) makes clear, a relativist could in principle make this concession and at the same time vindicate a different notion of faultless disagreement that appeals to a theoretical non-monadic notion of accuracy to explain the faultlessness of a disagreement. Appealing to this notion, the relativist could coherently say that the parties to a disagreement are fault free in the sense that each of them makes a sincere assertion that is accurate relative to her own context of assessment: in our working example, John would be fault free in the sense that his assertion is accurate as assessed from his context,

\footnotetext{
14 Thus, a disagreement should be understood here as involving the preclusion of the joint accuracy of two judgments or assertions (as assessed from a single context). (MacFarlane 2014, pp. 125-128)
}

Manuscrito - Rev. Int. Fil. Campinas, v. 40, n. 2, pp. 39-70, abr-jun. 2017. 
whereas Ann would be fault free in the sense that her assertion is accurate as assessed from her context. What is meant to create trouble for the relativist is the following dilemma that Boghossian (2011, p. 63) derives from the Argument from Immersion (the formulation that follows is mine, not Boghossian's):

Dilemma: The relativist can either accept the Argument from Immersion as sound or reject it as unsound. If she accepts it as sound, she needs to admit that truth relativism is unstable. If she rejects it as unsound, she has to give up some essential tenet of this view. Therefore, truth relativism is unstable.

To be sure, in order to make sense of this dilemma, we must, following Boghossian (2011, p. 63), make one further assumption (the formulation that follows is mine, not Boghossian's):

Committed Relativism: The theorist proposing a truth relativist treatment of $p$ can be a committed assessor regarding $p$ (i.e. it can happen that from her context $p$ is true, false or lacks a truth-value and the assertions of $p$ are accurate or inaccurate).

This seems not to be a problematic assumption. Relativists see themselves as providing an account of what is for anyone, including them, to judge that $p$. Thus, according to Committed Relativism, in case John were a relativist and realized that Ann's assertion that mutton is not tasty could be accurate as assessed from Ann's context because of the asserted proposition being true as assessed from this context, he would still be entitled to judge this proposition as simply false and Ann's assertion as simply inaccurate. And, of course, the same goes for Ann and her judgment of John's assertion. Let us now explain the just stated dilemma, especially in connection with MacFarlane's proposal, and see why it would reveal a special difficulty to provide an illuminating definition or characterization of MacFarlane's non-monadic truth notion in terms of the monadic ordinary one.

With respect to the first horn of the dilemma (i.e. the instability of truth relativism once the Argument from Immersion is accepted),

Manuscrito - Rev. Int. Fil. Campinas, v. 40, n. 2, pp. 39-70, abr.jun. 2017. 
Boghossian (2011, pp. 63-64) argues that in case a committed relativist endorsed the Argument from Immersion, she would have to concede that there is only one correct position to take about a given question subject to a relativist treatment (e.g. whether mutton is tasty). This is implied by the fact that she is committed to judge anyone having a view on this question that conflicts with her own to be mistaken (inaccurate). But then, the argument goes, the proposal the relativist ends up holding seems not to be relativist.

The problem would have to do with an instability in the proposal itself. Truth relativism about, say, predicates of personal taste (e.g. 'tasty'), holds that the truth or untruth of the propositions commonly expressed by simple sentences containing these predicates (e.g. 'Mutton is tasty') is relative to standards of taste. But a committed relativist who, like John, thinks that mutton is tasty must hold that anyone who thinks otherwise about mutton is mistaken (inaccurate), even if this person makes her judgment impeccably from her own different taste standard. So, what could be the committed relativist's attitude towards such a different standard of taste? The answer is that she must regard it as mistaken, given that she judges anyone who makes impeccable assessments according to it to be mistaken. That is, the committed relativist must see this standard as wrongly classing some things as tasty and others as not tasty. Thus, it seems that the committed relativist cannot say that the truth-value of the propositions expressed by means of sentences containing "tasty" can vary across contexts of assessment fixing different taste standards, since she considers that there is only one right standard of taste relative to which assessments for monadic truth should be made. According to Boghossian, then, intolerance about others' taste standards threatens to destabilize the central relativist tenet that certain propositions can have different truth-values relative to different standards of taste. Analogous remarks could be made about a relativist treatment of other expressions than predicates of personal taste.

To be sure, it could be argued that the first horn of the dilemma rests on the assumption that the monadic notion of rightness is absolute (i.e. assessment insensitive), but on MacFarlane's view this notion should be seen as assessment sensitive precisely as a result of the assessment sensitivity of monadic accuracy, which in turn is the result of the

Manuscrito - Rev. Int. Fil. Campinas, v. 40, n. 2, pp. 39-70, abr.-jun. 2017. 
assessment sensitivity of ordinary truth. That is, on this view, the right value of a parameter in the circumstances that is initialized by the context of assessment could vary with the context of assessment. Therefore, the argument goes, considering a particular parametric value (e.g. a standard of taste) as the only right one is compatible with endorsing truth relativism, which is a theory that would account, by means of a non-monadic truth notion, for the assessment sensitivity of ordinary truth.

This answer, as it stands, is insufficient to answer the dilemma's first horn. It is natural to take the relativist theory's metalanguage used to talk about truth relative to contexts of assessment, as providing an absolute and neutral point of view from which no assessment sensitive distinction between right and wrong parametric values initialized by the context of assessment is made. According to this, from the point of view of this language, two actual contexts fixing different parametric values would be equally appropriate standpoints for making assessments for ordinary truth. ${ }^{15}$ But a committed assessor could not occupy this point of view, insofar as she takes the value that her context fixes for a parameter initialized by the context of assessment (e.g. a given standard of taste) as the only right one for making such assessments (e.g. she should take all other taste standards than her own as wrongly classing some things as tasty and others as not tasty). In other words, assuming the default understanding of the relativist metalanguage, the commitment of the assessor implies her confinement to a perspective jointly provided by the object language and her context, from which she cannot coherently state the relativist view. Thus, the committed relativist needs to say something else in order to answer the just presented instability charge and so make proper sense of the non-monadic truth predicate she uses to relate propositions to contexts of assessment fixing possibly different parametric values. As these comments suggest and we shall see in the fourth section, she should introduce some form of assessment sensitivity

15 The restriction to actual contexts (i.e. contexts belonging to the actual world) is due to the fact that we should privilege the actual world in our assessments for ordinary truth. Similarly, in a framework that countenances time-neutral propositions, we should privilege the present time in such assessments.

Manuscrito - Rev. Int. Fil. Campinas, v. 40, n. 2, pp. 39-70, abr.jun. 2017. 
in the understanding of her metalanguage, and so deny that this language provides an absolute standpoint. But let us leave this issue aside for now and turn to the second horn of the dilemma (i.e. the impossibility for the relativist to reject the Argument from Immersion).

The scenario resulting from the relativist's acceptance of the argument from immersion gives her reason to reject it. But there is no way for the relativist to reject this argument. Rejecting premise 1 of the Argument from Immersion does not make sense, since it just presents a case of incompatible judgments. 2 and 5 cannot be rejected, since they characterize a case that relativists are committed to accept: 2 presents two contradictory propositions that can be both true relative to different contexts of assessment, whereas 5 -together with 2- implies that accuracy is assessment sensitive just as truth is. 3 seems unquestionable: if $p$ is true (from a context of assessment), then surely the proposition that it is true that $p$ is true (from this same context of assessment). We cannot reject 4 , since it just states a minimal requirement for coherence: it rules out the possibility of true contradictions. Rejecting the inference to 6 is not an option, since it is definitional that if someone can correctly judge that at least one party to a disagreement is mistaken, she cannot regard the disagreement as faultless (assuming that the notion of fault used in the whole argument is the ordinary monadic one). Finally, as we have suggested, there are good reasons for making the inference to 7 . But 7, as Boghossian (2011, 65) points out, is not necessary for the dialectic effectiveness of the dilemma. Therefore, the argument goes, truth relativism cannot avoid the instability charge. ${ }^{16}$

16 The relativist could also try to avoid Boghossian's dilemma by rejecting Committed Relativism. That is, she could claim that, from the context occupied by someone who knows the truth of the relativist theory, the propositions subject to a relativist treatment cannot be assessed for monadic truth, and so the assertions of these propositions cannot be assessed for monadic accuracy. According to this, speakers who sincerely and rationally predicate ordinary truth or untruth of these propositions need to ignore the truth of the relativist theory. This does not seem to be a plausible answer, insofar as most relativists think of themselves as regular speakers who make regular judgments expressed by means of those object language expressions subject to a relativist treatment (e.g. personal taste predicates, epistemic modals or the verb 'know'). In MacFarlane's

Manuscrito - Rev. Int. Fil. Campinas, v. 40, n. 2, pp. 39-70, abr.-jun. 2017. 
To close this section, let us see how the dilemma points to an apparent impossibility faced by the committed relativist to explain the notion of truth relative to a context of assessment in terms of ordinary monadic truth. As we argued in the previous section, in order to make sense of the former notion (i.e. show that it is a truth notion), the relativist should at least provide an illuminating definition of it in terms of the monadic notion of truth.

Suppose the committed relativist occupies a context of assessment $c$ where standard of taste $s$ is relevant and there are other contexts of assessment where other standards of taste are relevant. According to the dilemma's first horn, the monadic and assessment sensitive notion of accuracy derived from an allegedly ordinary assessment sensitive notion of truth, leads the committed relativist to take $s$ as the only right standard for truth-value assessments, and this destabilizes her basic tenet that truth is relative to contexts of assessment fixing possibly different taste standards. More to the point, according to this horn of the dilemma, if the relativist sincerely applies the ordinary and allegedly assessment sensitive truth notion, she cannot coherently see the truth predicate that relates propositions to contexts of assessment fixing possibly different parametric values as expressing a truth notion. For instance, John could not at the same time understand this non-monadic truth predicate as expressing a truth notion, and judge -using the standard of taste in play in his context- that Ann is simply wrong in asserting that mutton is not tasty because of the asserted proposition not being true.

The dilemma, then, is based on the apparent impossibility for the committed relativist to make sense of the notion of truth relative to a context of assessment in terms of the ordinary monadic truth notion. Accordingly, the dilemma -in particular its first horn- could be answered by means of a characterization of the notion of truth relative to a context of assessment in terms of ordinary monadic truth that allows us, at the same time, to see the former notion as a truth notion and the latter one as assessment sensitive.

words: "...committed relativists about some area of discourse will want the conveniences afforded by a disquotational truth predicate when they are engaging in that discourse." $(2011,442)$

Manuscrito - Rev. Int. Fil. Campinas, v. 40, n. 2, pp. 39-70, abr.jun. 2017. 
As we saw in this section, an illuminating characterization of the notion of truth relative to a context of assessment in terms of monadic truth has to provide an answer to Boghossian's dilemma, and the pull of this dilemma can be due to the default understanding of the metalanguage from the relativist theory. In the next section I explain in more detail what -I think- this understanding is, and argue that under this metalanguage understanding there is, as a matter of fact, no definitional link between ordinary truth and the relativist non-monadic truth notion that allows us to answer Boghossian's dilemma. In the fourth and fifth sections we shall consider the question of which metalanguage understanding could help the relativist solve this dilemma.

\section{Characterizations under the default metalanguage interpretation}

I take it that the default interpretation of the relativist metalanguage rests on the following two assumptions:

(I) Actual contexts constitute equally legitimate standpoints from which to make assessments for ordinary truth.

(II) One's understanding of the metalanguage is not dependent on the particular context one occupies.

According to this interpretation of the relativist metalanguage, despite the assessment sensitivity of truth and accuracy at the level of the object language, the relativist theory provides a neutral and absolute point of view at the level of the metalanguage. As we shall argue in the next section, truth relativism should reject both (I) and (II) in order to provide an explanation of non-monadic truth in terms of ordinary monadic truth that solves Boghossian's dilemma. Let us consider now why truth relativism cannot provide such an explanation once (I) and (II) are jointly endorsed.

There are two strategies for linking a monadic notion or property to a non-monadic -let us say dyadic- one that allow us to characterize one in

Manuscrito - Rev. Int. Fil. Campinas, v. 40, n. 2, pp. 39-70, abr.-jun. 2017. 
terms of the other. ${ }^{17},{ }^{18}$ To begin with, we can either fix one of the relata of the dyadic notion or establish a condition on it. This procedure would allow us to explain the dyadic truth notion relating propositions to possible worlds in terms of our ordinary truth notion. Everyday talk about truth concerns the world we inhabit, and so we can view the (monadic but structurally complex) notion of truth in the actual world as equivalent to our ordinary monadic truth notion. In turn, we could explain our talk of a proposition being true, untrue or false in non-actual worlds by appealing to our counterfactual talk about truth: to say that a proposition is true/ untrue/false in a non-actual world $w$ is equivalent to saying that it would be true/ untrue/false if such and such were the case. Similarly, if one accepts time-neutral propositions, one may be willing to see truth at present as equivalent to truth and take one's talk of a proposition being true, untrue or false at another time $t$ as equivalent to either saying that $p$ was true/ untrue/false when toccurred (if $t$ is in the past) or saying that $p$ will be true/ untrue/false when toccurs (if $t$ is in the future).

Secondly, if the extension of the monadic notion depends on the value of a parameter in the circumstances that corresponds to one of the argument places of the dyadic notion, we can link these notions by means of an operator. As MacFarlane (2011, p. 446) suggests, we can use an operator 'by $s$ ' (where $s$ could be, for instance, a taste standard, a knowledge standard or an information state) to formulate the following biconditional that links a non-monadic truth notion to a monadic one: proposition $p$ is true relative to $s$ iff by $s, p$ is true. Note that this biconditional should be read as a schema, since in order for it to state something general we must understand ' $s$ ' and ' $p$ ' as schematic letters.

With respect to the first linking strategy, one could think that it is possible for the relativist to take truth at her own context of assessment $c$

${ }^{17}$ I talk about a dyadic notion or property for the sake of simplicity. We can make the same points about a monadic notion and a non-monadic one of any adicity.

${ }^{18}$ It is worth noting that the provided link, as such, does not tell us which of the notions is taken as explanatory prior. In principle, we can use the link to characterize any of the two notions in terms of the other. Be that as it may, we are here considering our monadic truth notion as explanatory prior.

Manuscrito - Rev. Int. Fil. Campinas, v. 40, n. 2, pp. 39-70, abr.jun. 2017. 
or, better, truth at all contexts of assessment fixing the same parametric values as $c$ does, as equivalent to truth. One could then try to provide some explanation that links our talk of a proposition being true relative to a context of assessment $c$ ' that fixes different parametric values from the ones $c$ fixes, to our talk of a proposition being true. But under the default interpretation of the relativist metalanguage resulting from the joint acceptance of (I) and (II), we cannot apply this linking strategy.

According to this metalanguage interpretation, there cannot be a privileged set of actual and present contexts of assessment, and so one cannot saturate the context of assessment variable of the non-monadic truth predicate to provide an explanatory link between the notion this predicate expresses and ordinary truth. Recall that according to (I), actual contexts are equally legitimate truth assessment standpoints, while according to (II), one's understanding of the metalanguage is not dependent on the particular context one occupies. As a result, from the metalanguage standpoint, considering one particular set of contexts of assessment fixing the same parametric values as the only one relevant for assessing propositions for ordinary truth, is not only arbitrary but also incompatible with the purpose of relativizing truth and accuracy. Returning to our working example, John could not, under the default interpretation of the relativist metalanguage, take truth as equivalent to truth relative to all contexts of assessment where -like in his current context- the standard of taste he endorses prevails, and the same goes for Ann and the different taste standard she endorses.

In turn, using the second linking strategy a relativist could try to provide an explanation by means of the following biconditional schema (where $s_{c}$ stands for the value that $c$ fixes for parameter $s$ ):

Biconditional: Proposition $p$ is true relative to context of assessment $c$ iff by $s_{c}, \mathrm{p}$ is true. ${ }^{19}$

${ }^{19}$ For the sake of simplicity, we are ignoring the use sensitivity or assessment sensitivity of truth in connection with other parameters than $s$.

Manuscrito - Rev. Int. Fil. Campinas, v. 40, n. 2, pp. 39-70, abr.-jun. 2017. 
Since Biconditional is a schema, ' $c$ ' and ' $p$ ' are not taken to respectively name a particular context and a particular proposition but are seen as schematic letters respectively ranging over different contexts of assessment and propositions. In understanding $c$ in such a way we could hope to avoid the problem found with the first linking strategy: as a schema, Biconditional would allow us to have a grasp of the link between the two truth notions from an objective point of view that does not favor a particular parametric value and set of contexts of assessment.

However, Biconditional does not provide a characterization of the relativist's non-monadic truth notion in terms of monadic truth that helps her answer the first horn of Boghossian's dilemma. More to the point, the right hand side of Biconditional does not provide any explanation of how an assessor -in particular, the committed relativistcould take a certain parametric value (e.g. a standard of taste) as the only right one for truth-value assessments without being an absolutist. According to the dilemma's first horn, if John were a committed relativist, he would have trouble accepting all instances of this biconditional schema where a different taste standard from the one he endorses is mentioned, given that he would be committed to take any such standard as inappropriate for truth-value assessments. And the same goes for Ann and the different standard of taste she endorses.

In sum, we cannot state the truth relativist theory using exclusively the object language with its truth and accuracy notions, but, on the other hand, the default interpretation of this theory's metalanguage resulting from the acceptance of (I) and (II), prevents the relativist from providing a definitional link between non-monadic truth and ordinary truth that allows her to answer Boghossian's dilemma.

\section{Characterizations under an intra-contextual metalanguage interpretation}

There is an alternative interpretation of the relativist's metalanguage that may allow her to solve Boghossian's dilemma by applying the first linking strategy. Be that as it may, as we shall see in the next section, this move faces a further challenge.

Manuscrito - Rev. Int. Fil. Campinas, v. 40, n. 2, pp. 39-70, abr.jun. 2017. 
The relativist can try to make sense of her non-monadic truth notion by rejecting assumption (II) (i.e. one's understanding of the relativist metalanguage is not dependent on the particular context one occupies) and adopting an intra-contextual approach. In order to do this, she needs to offer an alternative understanding of her metalanguage. We shall consider two possible intra-contextual characterizations of non-monadic truth; the clear flaw of the first one will guide us to the second better one. As we shall see, whereas the first characterization does not require us to also drop assumption (I) (i.e. actual contexts are equally legitimate truth assessment standpoints), the second one does.

Suppose that an assessment sensitive proposition $p$ is untrue (true) relative to context of assessment $c$ and true (untrue) relative to context of assessment $c$. It can be thought that a relativist occupying $c$ can reason as follows: $p$ is untrue (true) but it would be true (untrue) if I were in $c^{\prime} /$ if I were to assess $p$ at $c^{\prime}$. Accordingly, as Montminy's $(2009,351)$ suggests, ${ }^{20}$ one could think possible to explain the relativist non-monadic truth notion by taking truth relative to context of assessment $c$ (one's own context) to be equivalent to truth, and understanding the theoretical talk of a proposition $p$ being true (untrue) relative to context of assessment c' (a context one does not occupy) as equivalent to saying, using the ordinary monadic truth notion, that $p$ would be true (untrue) if I were in $c^{\prime} /$ if I were to assess $p$ at $c^{\prime 21}$

20 Montminy (2009, 351-352) considers this explanation specifically in connection with the case of knowledge ascriptions and criticizes it because of contravening speakers' truth-value intuitions. As we shall see, contrary to Montminy's opinion, this explanation does not square well with truth relativism.

${ }^{21}$ Two worries could be raised. First, it can be argued that we should find a more colloquial way of explaining the sense of the non-monadic truth predicate. It is possible to do this by describing the relevant features of a context of assessment. For instance, Montminy (2009, p. 351) suggests the following way of explaining, from a context where a high knowledge standard is in play, our theoretical talk of the proposition that $S$ knows that $p$ being true relative to a context of assessment where a low knowledge standard is in play: if the stakes were low and no error possibilities had been mentioned, it would be true that $S$ knows that $p$. Second, it may be claimed that if one understands contexts as essentially having a particular agent, one cannot conceive of the possibility of

Manuscrito - Rev. Int. Fil. Campinas, v. 40, n. 2, pp. 39-70, abr.-jun. 2017. 
But according to MacFarlane (2014, p. 197), in the paradigmatic cases of an assessment sensitive proposition $p$, the proposition expressed by ' $p$ would be true (untrue) if I were in $c^{\prime} /$ if I were to assess $p$ at $c^{\prime}$ is false as assessed from my context $c{ }^{22}$ The antecedent of this counterfactual conditional (i.e. 'if I were in $c^{\prime} /$ if I were to assess $p$ at $c$ ") shifts the value of the possible world parameter but not the parametric value that is fixed by the context of assessment (e.g. a taste or knowledge standard). As a result, on MacFarlane's view I can say truly from my context of assessment $c$ that if I were in $c^{\prime} /$ if I were to assess $p$ at $c^{\prime}$, I would come up with the wrong verdict concerning $p$ 's truth-value or lack thereof.

Notice that this is not just what MacFarlane says but also the natural thing for a relativist to say. In taking truth as assessment sensitive the relativist takes accuracy as assessment sensitive as well: since a context of use alone does not determine a truth-value or lack thereof for an assessment sensitive proposition, we cannot assess for accuracy an assertion that has such a proposition as content without a context of assessment. Thus, in a case where person asserts a proposition $p$ that is true as assessed from her context $c^{\prime}$ but is untrue as assessed from my context $c$, the relativist considers that, from my context $c$, this assertion is inaccurate because of $p$ being untrue. But if this is so, why should I judge that if I were in $c^{\prime}$ (or in a context fixing the same parametric values as $c^{\prime}$ does) $p$ would be true and so I would be right in assessing this proposition as true? Rather, I should judge that I would be wrong just as this person actually occupying $c$ 'is. Then, the explanation suggested by

being in a context $c^{\prime}$ that is actually occupied by another person. If one had this worry concerning a context $c$, one could reformulate the just given explanation of truth relative to context of assessment c' by talking of the possibility of being in a context that has the same relevant features as $c^{\prime}$ has, or fixes the same parametric values as $c$ 'does.

22 MacFarlane (2014, p. 197) stresses this point just to refute Montminy's (2009, 351-352) claim that truth relativism is committed to counter-intuitively take a counterfactual like this one as true. MacFarlane does not consider in his book other possible definitions of truth relative to a context of assessment, since he adopts a different approach to make sense of this notion.

Manuscrito - Rev. Int. Fil. Campinas, v. 40, n. 2, pp. 39-70, abr.jun. 2017. 
Montminy conflicts with the way the relativist thinks that assertions made at other contexts are to be assessed.

Given that we are trying to provide a characterization from our own context of assessment $c$, it seems clear that we should see truth as equivalent to truth relative to $c$ or, better, as equivalent to truth relative to contexts $C$ (all contexts fixing the same parametric values as the ones our context fixes). The difficulty arises in providing something extensionally equivalent to truth relative to a context of assessment $c$ ' (a context of assessment one does not occupy and that fixes different parametric values from the ones our context fixes) by using our ordinary monadic truth notion. The problem faced by Montminy's linking explanation suggests that we need to shift the parametric value(s) fixed by the context of assessment in a way that is compatible with how speakers are supposed to assess assertions of assessment sensitive propositions.

One could try to make sense of our talk of a proposition $p$ being true relative to a context of assessment $c^{\prime}$ by appealing to the following counterfactual talk: $p$ would be true if context $c$ ' were a right context of assessment, that is if the parametric values (e.g. a standard of taste) that $c^{\prime}$ (as a context of assessment) fixes were the right ones. ${ }^{23}$ According to this explanation of the relativist non-monadic truth notion, a relativist should privilege her own context of assessment by considering it as a right one, and claim that her view is still relativist insofar as she considers that it is not possible in certain areas (e.g. matters of taste) to occupy an absolute point of view concerning what is right. What is right (e.g. a given taste standard and the contexts where it prevails) would vary with the context of assessment, and so the notion of rightness would be assessment sensitive. In our working example, John could coherently accept the relativist theory and consider his own standard of taste as the only right

\footnotetext{
${ }^{23}$ MacFarlane's post-semantic truth notion is actually a triadic notion relating propositions to contexts of assessments and contexts of use. According to what was just said, for a context $c_{1}$ and a context $c_{2}$ that fixes different parameteric values from the ones our context fixes, one could explain the sense of ' $p$ is true as used at $c_{1}$ and assessed from $c_{2}$ ' by means of a locution like the following: 'if $c_{2}$ were a right context of assessment, by the parametric values that $c_{1}$ and $c_{2}$ respectively fix, $p$ would be true.'
}

Manuscrito - Rev. Int. Fil. Campinas, v. 40, n. 2, pp. 39-70, abr.-jun. 2017. 
one, given that -as a relativist- he should take the notion of rightness as assessment sensitive. As a result, John could be a relativist and judge that Ann is simply wrong in claiming that mutton is not tasty. Thus, accepting this proposal amounts to dropping not just assumption (II) (i.e. one's understanding of the relativist metalanguage is not dependent on the particular context one occupies), but also assumption (I) (i.e. actual contexts constitute equally legitimate truth assessment standpoints).

Note that the proposed explanation of the notion truth relative to a context of assessment does not face the problem that the explanation suggested by Montminy faces. In conferring a privileged status on our context, the proposed explanation is compatible with correctly assessing (from our context) as inaccurate an assertion made at a context from which the asserted proposition is true: since this context of assessment is not right and from our right context the proposition asserted is untrue, this assertion is inaccurate. Accordingly, our explanation could solve Boghossian's dilemma by rebutting its first horn (i.e. the instability of truth relativism once the Argument from Immersion is accepted).

This answer to the dilemma, then, does not reject the Argument from Immersion. The notion of fault (i.e. the notion of inaccuracy) used in this argument would be a monadic assessment sensitive one, and there cannot be faultless disagreements once this is the notion of fault at stake. But, by having made sense of truth relative to a context of assessment, the relativist would have made sense of accuracy relative to a context of assessment as well, and so she could vindicate a notion of faultless disagreement that appeals to this non-monadic notion of accuracy to explain the faultlessness of a disagreement: in our working example, John would be fault free in the sense that his assertion would be accurate as assessed from his context, whereas Ann would be fault free in the sense that her assertion would be accurate as assessed from her context.

Be that as it may, there is an important challenge lurking behind this solution: to give an explanation of what the rightness of a parametric value and a context of assessment amounts to. As we pointed out, the notion of rightness itself should be seen as assessment sensitive (i.e. what is right can vary across contexts of assessment), and so the proposal, as it stands, is non-illuminating. In the next section I consider this task that the

Manuscrito - Rev. Int. Fil. Campinas, v. 40, n. 2, pp. 39-70, abr.jun. 2017. 
relativist needs to accomplish in order to provide an illuminating characterization of her non-monadic truth notion.

\section{The task left to the relativist}

If the relativist does not explain or motivate an assessment sensitive notion of rightness as applied to parametric values and contexts of assessment, she cannot show that her view is stable and so rebut the first horn of Boghossian's dilemma. Without this explanation, our characterization of the relativist non-monadic truth notion can be accused of making truth relativism collapse into an absolutist position that provides no justification for the rightness of some contexts of assessment and the wrongness of others. In other words, it can be accused of making truth relativism collapse into a chauvinist kind of absolutism.

To be sure, the explanation of what the rightness of a parametric value or context of assessment amounts to should be considered with respect to each particular case subject to a relativist treatment. That is, it should be considered with respect to particular forms of assessment sensitivity arising from different sorts of features of contexts of assessment that would affect the extension of the ordinary truth notion. For instance, we can attempt to explain the rightness of the standard of taste, the standard of knowledge or the information state that is contextually relevant in order to respectively make sense of relativism about predicates of personal taste, relativism about knowledge ascriptions or relativism about epistemic modals.

There are better prospects of motivating this notion of rightness in the case of evaluative predicates like personal taste, moral or aesthetics predicates than in the other cases that were mentioned. People endorse a taste, moral or aesthetic standard as a result of their preferences and values. Such an endorsement seems (especially in the moral case) indispensable to people's lives and, as Barry C Smith $(2010,2012)$ argues, gives rise to disagreements that seem intractable (i.e. impossible in principle to be solved or dissolved by rational means). Arguably, people tend to see those individuals who endorse a taste, moral or aesthetic

Manuscrito - Rev. Int. Fil. Campinas, v. 40, n. 2, pp. 39-70, abr.-jun. 2017. 
standard clearly different from their own as mistaken. It is natural to judge someone who sees as morally right an action we consider to be a crime as being wrong, or to judge someone who sees as aesthetically worthy a piece of music we consider that is poorly written as being mistaken. But at the same time, there would be little we could say to make someone rationally change such an opinion, insofar as this opinion is the result of a personal endorsement of a standard different from our own. And it seems that even if we were rational and aware of the fact that this person endorsed a different standard, we would not be easily disposed to say that her judgment is as valid as ours. In order to show that this also happens in connection with matters of taste, Smith (2010) analyzes a seemingly intractable dispute actually held by two wine critics over whether a particular new wine was tasty; despite being aware of all the criteria that each of them were using to judge the wine, these critics would have been unable to solve or dissolve their disagreement. According to this line of reasoning, people usually take their own taste, moral or aesthetic standard as the only right one, even if rational and knowledgeable. Truth relativism could vindicate this behavior and so the intractability of the previous disagreements by taking someone's taste, moral or aesthetic standard as actually being the right one from her context of assessment.

I doubt that we can adequately motivate an assessment sensitive notion of rightness in the case of knowledge ascriptions or epistemic modals. And even if in the case of personal taste, moral and aesthetic predicates, the relativist could say something substantial in this respect, her opponent could always reintroduce the instability charge and contend that Boghossian's dilemma has not really been solved. More precisely, the non-relativist can always claim that there is an inevitable tension between the committed relativist's idea that she is entitled to consider certain contexts of assessment as the right ones and her idea that there is no inter-contextual (absolute) reason favoring these contexts over others. After all, it is expectable that the relativist and her opponent at some point reach a deadlock when arguing with each other.

Manuscrito - Rev. Int. Fil. Campinas, v. 40, n. 2, pp. 39-70, abr.-jun. 2017. 


\section{Final remarks}

I have considered the question of whether the relativist can make sense of the notion of truth relative to a context of assessment. First, I argued that, in order to do this, the relativist must at least provide an illuminating characterization of this notion in terms of ordinary truth. MacFarlane's different approach to make sense of relative truth can be useful, but the characterization approach should not be discarded. Second, I argued that an illuminating characterization of truth relative to a context of assessment has to answer Boghossian's dilemma. This dilemma, which Boghossian (2011) derives from the Argument from Immersion, is based on the impossibility to define or characterize the relativist nonmonadic truth notion in terms of monadic truth under the default understanding of the relativist metalanguage. Third, I singled out an alternative interpretation of this metalanguage that provides a characterization of truth relative to a context of assessment that could answer Boghossian's dilemma. This characterization is based on an allegedly assessment sensitive notion of rightness that is applied to parametric values and contexts of assessment. Finally, I have shown that the relativist still needs to make proper sense of this solution by giving an explanation of what the rightness of a parametric value or context of assessment amounts to in each case subject to a relativist treatment. There are better prospects of motivating this notion of rightness in the case of evaluative predicates like personal taste, moral or aesthetics predicates than in other cases. Be that as it may, whether this task can be successfully accomplished is a question this essay leaves open.

\section{References}

Boghossian, P. “Three kinds of relativism.” In S. D. Hales (ed.) (2011), pp. 53-69.

CAPpelen, H., HAwTHORne, J. "Reply to Lasersohn, MacFarlane and Richard”. Philosophical Studies, 156 (3), pp. 449-466, 2011.

Manuscrito - Rev. Int. Fil. Campinas, v. 40, n. 2, pp. 39-70, abr.-jun. 2017. 
Press, 2009.

DummetT, M. "Truth." Proceedings of the Aristotelian Society, 59 (1), 141162, 1959.

Truth and Other Enigmas. Cambridge: Harvard University Press, 1978.

Relativism and Monadic Truth. Oxford: Oxford University 
Recanati, F. Stojanovic, I., Villanueva, N. Context-Dependence, Perspective and Relativity. Berlin/New York: De Gruyter Mouton, 2010.

SMITH, B. C. "Relativism about truth and predicates of taste." Filosofia Unisinos, 13 (2), pp. 250-265, 2012. "Relativism, disagreement and predicates of personal taste." In F. Recanati, I. Stojanovic and N. Villanueva (eds.) (2010), pp. 195225.

SOAMES, S. “True at.” Analysis, 71 (1), pp. 124-133, 2011.

TARSKI, A. “The concept of truth in formalized languages." In A. Tarski (1956), pp. 152-278.

Logic, Semantics, Metamathematics: Papers from 1923 to 1938. Oxford: Clarendon Press, 1956. 